\section{Inert Gas Analysis of Ventilation-Perfusion Matching during Hemodialysis}

\author{
D. D. Ralph, S. M. Ott, D. J. Sherrard, and M. P. Hlastala \\ Departments of Medicine and Physiology and Biophysics, \\ University of Washington, Seattle, Washington 98195
}

bstract. The mechanism of hypoxemia during hemodialysis was investigated by the multiple inert gas elimination technique in anesthetized, paralyzed, mechanically ventilated dogs. Profound leukopenia occurred in the first hour of a 2-h hemodialysis with a cuprophan membrane and dialysate that contained acetate. Arterial partial pressure of $\mathrm{O}_{2}$ and $\mathrm{CO}_{2}$ and oxygen consumption remained unchanged during dialysis. Pulmonary carbon dioxide elimination and lung respiratory exchange ratio decreased with the initiation of dialysis, remained depressed throughout the duration of dialysis, and returned to predialysis levels after the cessation of dialysis. Cardiac output diminished during dialysis but did not return to base-line levels after dialysis. Multiple indices calculated from inert gas analysis revealed no ventilation-perfusion mismatching during dialysis. The shunt and perfusion to regions of low alveolar ventilation-to-perfusion ratio $\left(\dot{\mathrm{V}}_{\mathrm{A}}\right)$ Q) were unchanged during dialysis. There was no change in the mean or standard deviation of the profile of the percentage of total perfusion to regions of the lung that had $\dot{\mathrm{V}}_{\mathrm{A}} / \mathrm{Q}$ near 1.0; nor was there any increase in the directly calculated arterial-alveolar partial pressure differences for the inert gases during dialysis. Dead space became mildly elevated during dialysis. These results show that during dialysis with controlled ventilation there is no ventilation-perfusion mismatching that leads to hypoxemia. During spontaneous ventilation any hypoxemia must occur due to hypoventilation secondary to the $\mathrm{CO}_{2}$ exchange by the dialyzer and subsequent reduction in pulmonary $\mathrm{CO}_{2}$ exchange.

\section{Introduction}

Hypoxemia occurs in most patients during hemodialysis when the dialysate contains acetate $(1,2)$. Two major hypotheses have

Received for publication 27 June 1983 and in revised form 4 January 1984.

J. Clin. Invest.

(c) The American Society for Clinical Investigation, Inc.

0021-9738/84/05/1385/07 \$1.00

Volume 73, May 1984, 1385-1391 been advanced to explain such hypoxemia. Since some carbon dioxide diffuses out of the blood passing across the dialysis membrane, a normal arterial partial pressure of $\mathrm{CO}_{2}\left(\mathrm{P}_{\mathrm{a}} \mathrm{CO}_{2}\right)^{1}$ may be maintained with less $\mathrm{CO}_{2}$ removal by pulmonary ventilation $(3,4)$. Hypoxemia, then, may be a direct result of diminished alveolar ventilation (3-6). A second explanation for hypoxemia suggests that the pulmonary leukocyte aggregation caused by complement activation on the dialysis membrane interferes with ventilation-perfusion matching in the lung (2, 7,8 ). Aggregated leukocytes may mechanically alter blood flow or release toxic products that alter ventilation-perfusion matching (8-10).

Several previous studies have supported one or the other of these mechanisms. Many reports, however, have suffered from imprecision because not all multiple variables that affect gas exchange have been measured directly. We have applied the multiple inert gas elimination technique as a means to quantitate pulmonary gas exchange during dialysis. This method is independent of carbon dioxide and oxygen flux across the dialysis membrane. With this technique, small quantities of six inert gases with widely different solubilities are infused intravenously; resulting concentrations are measured in arterial blood, mixed venous blood, and exhaled air. Since the gases have different solubilities, their concentrations in the blood and gas phase are sensitive indicators of ventilation-perfusion matching. These measurements allow calculation of pulmonary shunt, dead space, and the degree of ventilation-perfusion (alveolar ventilation-to perfusion ratio $\left[\dot{\mathrm{V}}_{\mathrm{A}} / \mathrm{Q}\right]$ ) heterogeneity. Our results reveal no evidence of ventilation-perfusion mismatching during hemodialysis when ventilation is mechanically maintained at a constant rate.

\section{Methods}

9 mongrel dogs weighing 20-24 kg were anesthetized with thiopental sodium $(20-30 \mathrm{mg} / \mathrm{kg})$, intubated with a cuffed endotracheal tube, and mechanically ventilated with room air at a tidal volume of $15 \mathrm{ml} / \mathrm{kg}$ and at a rate sufficient to maintain an arterial $\mathrm{P}_{2} \mathrm{CO}_{2}$ of $32-36$ torr. Thereafter, ventilation was kept at a constant minute volume. Subsequent

1. Abbreviations used in this paper: (a-A)D; inert gas arterial-alveolar difference; $\mathrm{PaCO}_{2}$, arterial partial pressure of $\mathrm{CO}_{2} ; R$, lung respiratory exchange ratio $\left(\dot{\mathrm{V}}_{\mathrm{CO}_{2}} / \dot{\mathrm{VO}}_{2}\right) ; \dot{\mathrm{Q}}_{\mathrm{S}} / \dot{\mathrm{Q}}_{\mathrm{T}}$, shunt fraction; $\dot{\mathrm{V}}_{\mathrm{A}} / \mathrm{Q}$, alveolar ventilation-to-perfusion ratio; $\mathrm{VCO}_{2}, \mathrm{CO}_{2}$ elimination; $\dot{\mathrm{V}}_{2}$, oxygen consumption; $V_{D} / V_{T}$, dead space to tidal volume ratio; WBC, white blood cell. 
anesthesia and paralysis were maintained with intravenous pentobarbital $(60 \mathrm{mg})$ and pancuronium $(20 \mathrm{mg})$ given slowly every $30-60 \mathrm{~min}$ as needed to prevent spontaneous ventilation. Neither medication was given within the $10 \mathrm{~min}$ before any sampling time. Catheters were introduced into one femoral vein for the infusion of the inert gas mixture and into the ipsilateral femoral artery for pressure monitoring and arterial blood sample collection. The contralateral femoral artery and vein were cannulated for hemodialysis. A Swan-Ganz thermodilution pulmonary artery catheter (Edwards Laboratories, American Hospital Supply Corp., Santa Ana, CA) was inserted via a jugular vein into the pulmonary artery for pressure monitoring and collection of mixed venous blood samples. Exhaled respiratory gas was passed through a 6-liter mixing chamber before sampling.

To avoid excessive hypotension during dialysis, $200-300 \mathrm{ml}$ normal saline was infused before control measurements were obtained. A solution of six inert gases (sulfur hexafluoride, ethane, cyclopropane, halothane, diethyl ether, and acetone) in 5\% dextrose in water was infused through a peripheral vein at a rate of $3 \mathrm{ml} / \mathrm{min}$ starting at least $30 \mathrm{~min}$ before the first set of studies. When hemodynamic parameters were stable for at least $15 \mathrm{~min}$ after the saline infusion, the control set of hemodynamic measurements and blood and exhaled gas samples were obtained (time 0 ). Hemodialysis was then performed for $2 \mathrm{~h}$ against a standard acetatecontaining dialysate. The dialyzers had a cuprophane membrane with surface area of $0.54-1.0 \mathrm{~m}^{2}$. Blood flow was $90-175 \mathrm{ml} / \mathrm{min}$ through the dialyzer. In each individual dog, flow varied by $<25 \mathrm{ml} / \mathrm{min}$ during the experiment. Repeat hemodynamic measurements and sample collections were obtained after 5, 15, 30, 60, and 120 min of dialysis. Blood in the dialyzer was returned to the dog at the conclusion of dialysis and a final set of measurements and samples was obtained at 150 min (30 min after cessation of dialysis). Normal saline was infused during dialysis at a rate sufficient to replace the volume removed during dialysis $(\sim 100 \mathrm{ml} / \mathrm{h})$.

At each measurement period the systemic arterial pressure, pulmonary artery pressure, pulmonary artery wedge pressure, and thermodilution cardiac output (mean of three injections agreeing within $10 \%$ ) were recorded. Constancy of exhaled minute ventilation was confirmed by measurement with a Collins spirometer (Warren E. Collins, Inc., Boston, MA). Venous white blood cell count (WBC) was measured by a Coulter counter (Coulter Electronics, Inc., Hialeah, FL). Arterial and mixed venous blood samples were obtained for measurement of $\mathrm{PO}_{2}$ and $\mathrm{PCO}_{2}$ (MKS Mark II blood gas analyzer; Radiometer America, Inc., Westlake, $\mathrm{OH}$ ) and inert gas concentrations (inert gas measurements were made at the 5-min sampling period in only four dogs). During 16 dialysis measurements in six dogs, blood returning to the dog from the dialyzer was also sampled for blood gases. The rate of $\mathrm{CO}_{2}$ removal by the dialyzer was calculated as the product of the dialyzer blood flow and the $\mathrm{CO}_{2}$ content difference between blood flowing to and returning from the dialyzer. The $\mathrm{CO}_{2}$ elimination removed by dialysis was compared with the reduction in pulmonary $\left(\mathrm{V}_{\mathrm{CO}}\right)$ from the average of the preand postdialysis $\dot{\mathrm{V}} \mathrm{CO}_{2}$. The ratio of the $\mathrm{CO}_{2}$ removed by the dialyzer to the decrease in $\mathrm{CO}_{2}$ removed by the lungs was calculated. Mixed exhaled gas was sampled and kept heated to $40^{\circ} \mathrm{C}$ to void condensation of soluble inert gases in water vapor. After separation on a gas chromatograph the inert gases were measured with either an electron capture detector (SF6) or a flame ionization detector (11).

Several parameters of ventilation-perfusion matching were obtained from the inert gas results. The data were initially converted into the retention (arterial partial pressure/mixed venous partial pressure) and excretion (partial pressure in exhaled air/mixed venous partial pressure) ratios for each inert gas. First the methods of Evans and Wagner (12) and Wagner et al. (13) were used to convert inert gas retention and excretion values into a plot of percentage of total perfusion and ventilation to each of 50 compartments. These compartments include inert gas shunt $\left(\dot{\mathrm{V}}_{\mathrm{A}} / \dot{\mathrm{Q}}=0\right)$, inert gas dead space $\left(\dot{\mathrm{V}}_{\mathrm{A}} / \dot{\mathrm{Q}}=\infty\right)$, and 48 other compartments with $\dot{V}_{A} / Q$ ranging from 0.001 to 100 . The following parameters were calculated: $(a)$ the overall mean ventilation-to-perfusion ratio for the lung, $(b)$ the shunt flow $\left(\dot{\mathrm{Q}}_{\mathrm{S}} / \dot{\mathrm{Q}}_{\mathrm{T}}\right),(c)$ the flow to regions of low but finite $\dot{\mathrm{V}}_{\mathrm{A}} / \mathrm{Q}\left(0.001<\dot{\mathrm{V}}_{\mathrm{A}} / \mathrm{Q}<0.1\right)$, and $(d)$ the mean and standard deviation of the percent total perfusion (or ventilation distribution) to the 50 compartments. Shifts in the position (mean) or dispersion (standard deviation) of either the perfusion or ventilation distribution reflect changes in ventilation-perfusion matching; $(e)$ the inert gas dead space $\left(V_{D} / V_{T}\right)$ and physiological dead space are measurements of wasted ventilation. The retention and excretion data were also analyzed directly (14) to derive $(f)$, the inert gas arterial-alveolar difference ([a-A]D) area. This is calculated from the difference between the arterial and mixed expired partial pressure of each of the six inert gases plotted against inert gas solubility (14). The (a-A)D area is a measurement of the inhomogeneity of $\dot{V}_{A} / Q$ matching after correcting for effects of shunt and anatomical dead space; $(g)$ the relative $(\mathrm{a}-\mathrm{A}) \mathrm{D}$ area is the fraction of the (a-A)D area up to the mean $\dot{V}_{A} / Q$ of the lung. The relative (a-A)D area will decrease if there is a shift toward lower $\dot{V}_{A} / Q$ regions (14) and will increase if there is a shift toward higher $\dot{V}_{A} / \dot{Q}$ regions. Finally, $(h)$ the alveolar-arterial $\mathrm{PO}_{2}$ difference and $(i)$ the venous admixture were predicted from the inert gas analysis (12). Changes in measured variables during dialysis were compared by analysis of variance and the $t$ test (Clinfo computer program, Clinical Research Center grant RR-37).

\section{Results}

Nine dogs were studied. The first three dogs showed substantial leukopenia after the insertion of vascular catheters before starting dialysis. In the remaining dogs, such predialysis leukopenia did not occur since strict aseptic techniques were used during catheter insertion. The mean pulmonary artery pressure did not change with initiation of dialysis in these first three dogs, but it increased in the remaining dogs. Otherwise, there were no significant differences in hemodynamic or gas exchange results between the first three dogs and the subsequent six dogs. Data for all nine dogs are presented in the tables.

Hemodynamic changes (Fig. 1, Table I). Systolic and diastolic blood pressure fell in all dogs at the initiation of dialysis and remained decreased throughout dialysis. Cardiac output fell progressively during dialysis and increased after completion of dialysis, although it did not return to the control level. Pulmonary artery wedge pressure was unchanged. Mean pulmonary artery pressure increased promptly as soon as dialyzed blood began to return to the dogs and remained somewhat elevated throughout dialysis.

WBC counts (Fig. 2, Table I). In dogs 4-9, white cell counts decreased rapidly from $8,200 \pm 1,500 / \mathrm{ml}$ (mean \pm SEM) before dialysis to $2,400 \pm 200 / \mathrm{ml}$ within $5 \mathrm{~min}$ of the start of dialysis. The WBC count remained depressed during the first hour of dialysis but then rose progressively and was not different from control levels after $2 \mathrm{~h}$ of dialysis. A significant increase above the initial control WBC count occurred $30 \mathrm{~min}$ after dialysis was completed. 


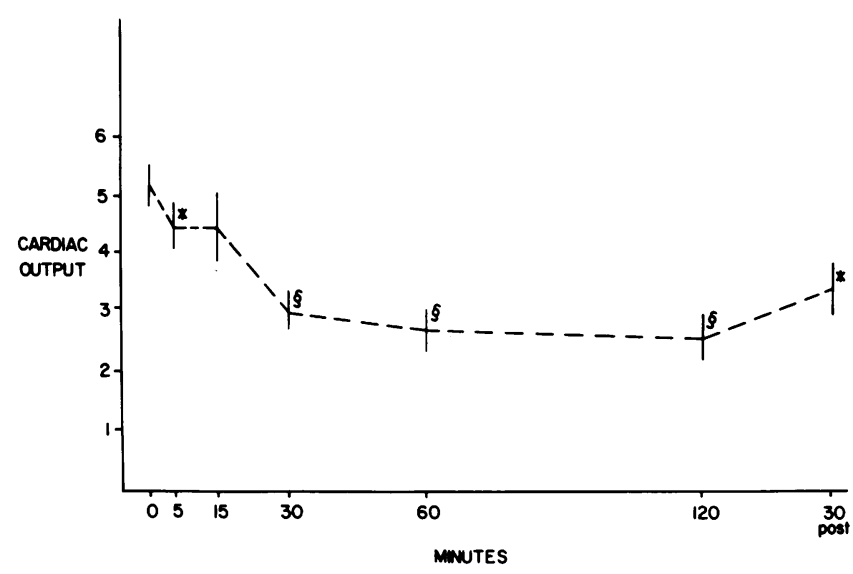

Figure 1. Cardiac output (liters per minute) during the experiment. The measurements from 5 to 120 min were during dialysis. Significance notation for all figures: $*, P<0.05$ vs. time $0 ; \ddagger, P<0.01$ vs. time $0 ; \S, P<0.001$ vs. time 0 . Values shown are mean \pm SEM.

Gas exchange (Table I). The mean measured $\mathrm{P}_{\mathrm{a}} \mathrm{O}_{2}$ showed no significant changes at any point during the experiment (Fig. $3)$. In three dogs, however, we noted a drop of $>10$ torr at the 5- or 15-min recordings, with a subsequent return to base line. Measured $\mathrm{P}_{\mathrm{a}} \mathrm{CO}_{2}$ was unchanged. Oxygen consumption did not change significantly during dialysis but there was a decrease in pulmonary $\mathrm{CO}_{2}$ exchange (Fig. 4), which was significant at all times after $15 \mathrm{~min}$ of dialysis. The resulting lung respiratory

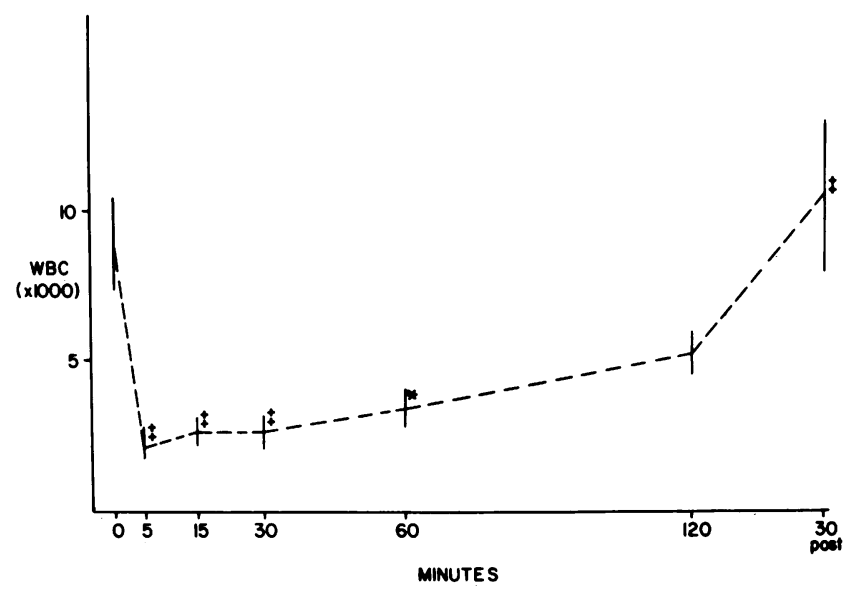

Figure 2. WBC count. See Fig. 1 legend for explanation of symbols.

exchange ratio $(R)$ decreased from $1.02 \pm 0.03$ before dialysis to $0.84 \pm 0.03$ during dialysis $(P<0.001)$. The ratio of calculated $\mathrm{CO}_{2}$ removal by the dialyzer to the decline in pulmonary $\mathrm{CO}_{2}$ removal from control levels was $0.82 \pm 0.33$. The mean $\dot{\mathrm{V}}_{2}$ removed by the dialyzer was $28.0 \pm 9.3 \mathrm{ml} / \mathrm{min}$.

Ventilation-perfusion matching (Table II). Parameters of ventilation-perfusion matching obtained from the inert gas retention and excretion did not indicate development of ventilation-perfusion mismatching that would lead to hypoxia during dialysis. The values remained normal, even in the three dogs

Table I. Measured Hemodynamic, Hematologic, and Gas-Exchange Parameters

\begin{tabular}{|c|c|c|c|c|c|c|c|}
\hline \multirow[b]{2}{*}{ Time } & \multirow{2}{*}{$\frac{\text { Control }}{0}$} & \multicolumn{5}{|l|}{ Dialysis } & \multirow{2}{*}{$\frac{\text { Control }}{150}$} \\
\hline & & 5 & 15 & 30 & 60 & 120 & \\
\hline \multicolumn{8}{|l|}{ Psystolic } \\
\hline$(m m H g)$ & $176 \pm 7^{11}$ & $158 \pm 15$ & $158 \pm 7 \ddagger$ & $141 \pm 11 \pi$ & $125 \pm 9 \S^{*}$ & $131 \pm 7 \S^{*}$ & $157 \pm 4 \pi$ \\
\hline \multicolumn{8}{|l|}{ Pdiastolic } \\
\hline$(\mathrm{mmHg})$ & $134 \pm 7^{\| \prime}$ & $110 \pm 10$ & $109 \pm 7$ & $98 \pm 8 \pi$ & $89 \pm 9 \S$ & $84 \pm 7 * \S$ & $104 \pm 4 \pi$ \\
\hline Ppaw $(m m H g)$ & $4.2 \pm 0.8$ & $4.8 \pm 1.1$ & $4.1 \pm 1.1$ & $3.8 \pm 0.9$ & $3.2 \pm 1.0$ & $3.4 \pm 1.0$ & $2.7 \pm 0.5$ \\
\hline $\mathrm{P} \overline{\mathrm{pa}}(\mathrm{mmHg})$ & $15.4 \pm 1.0$ & $26.0 \pm 0.2 \ddagger \pi$ & $20.0 \pm 1.6 \ddagger$ & $19.2 \pm 1.6$ & $17.6 \pm 0.9$ & $20.2 \pm 1.7$ & $20.0 \pm 2.0 \ddagger$ \\
\hline WBC $(1,000 / \mathrm{ml})$ & $8.2 \pm 1.5^{11}$ & $2.4 \pm 0.2^{\| \prime}$ & $2.9 \pm 0.4 q^{\prime \prime}$ & $3.3 \pm 0.6^{\prime \prime}$ & $4.0 \pm 0.7^{\prime \prime}$ & $6.2 \pm 0.9^{*}$ & $12.9 \pm 2.5 \pi$ \\
\hline $\mathrm{P}_{\mathrm{a}} \mathrm{O}_{2}$ (torr) & $84.1 \pm 2.5$ & $78.6 \pm 3.2$ & $80.7 \pm 3.9$ & $83.4 \pm 3.1$ & $80.6 \pm 3.5$ & $79.4 \pm 2.6$ & $82.7 \pm 1.3$ \\
\hline $\mathrm{P}_{\mathrm{a}} \mathrm{CO}_{2}$ (torr) & $34.5 \pm 1.1$ & $36.3 \pm 2.1$ & $34.3 \pm 1.0$ & $34.6 \pm 1.3$ & $34.4 \pm 1.5$ & $32.9 \pm 1.3$ & $36.4 \pm 1.9$ \\
\hline$\dot{\mathrm{V}}_{2}(\mathrm{ml} / \mathrm{min})$ & $173 \pm 8$ & $214 \pm 36$ & $172 \pm 12$ & $165 \pm 10$ & $161 \pm 9$ & $160 \pm 12$ & $172 \pm 11$ \\
\hline$\dot{\mathrm{V}} \mathrm{CO}_{2}(\mathrm{ml} / \mathrm{min})$ & $177 \pm 8$ & $165 \pm 22$ & $152 \pm 12$ & $138 \pm 7 \S^{\prime \prime}$ & $135 \pm 8 \S^{\prime \prime}$ & $132 \pm 9 \S^{* *}$ & $161 \pm 8$ \\
\hline$R$ & $1.02 \pm 0.03$ & $0.79 \pm 0.04 \S^{\prime \prime}$ & $0.89 \pm 0.05$ & $0.84 \pm 0.03 \S^{\prime \prime}$ & $0.84 \pm 0.03 \S^{*}$ & $83 \pm 0.03 \S^{\prime \prime}$ & $0.95 \pm 0.04$ \\
\hline \multicolumn{8}{|l|}{$V_{\mathrm{D}} / V_{\mathrm{T}}(\mathrm{Bohr})$} \\
\hline (\%) & $40.3 \pm 4.2$ & $42.9 \pm 3.3$ & $43.2 \pm 2.8$ & $52.5 \pm 4.1$ & $53.1 \pm 4.0$ & $51.3 \pm 3.6$ & $46.9 \pm 3.3$ \\
\hline
\end{tabular}

Values are mean $\pm \mathrm{SEM} . \dot{Q}_{\mathrm{T}}$, cardiac output; $P$, pressure; paw, pulmonary artery wedge; $P \overline{\mathrm{pa}}$, pulmonary artery mean. $\mathrm{P} \overline{\mathrm{pa}}$ and $\mathrm{WBC}$ are for dogs 4-9, other parameters are for all nine dogs (see text). $* P<0.05$; vs. 150 -time value. $¥ P<0.05$; vs. 0 -time value. $\S P<0.001$; vs. 0 time value. " $P<0.01$; vs. 150 -time value. $\pi P<0.01$; vs. 0 -time value. ${ }^{* *} P<0.001$; vs. 150 -time value. 


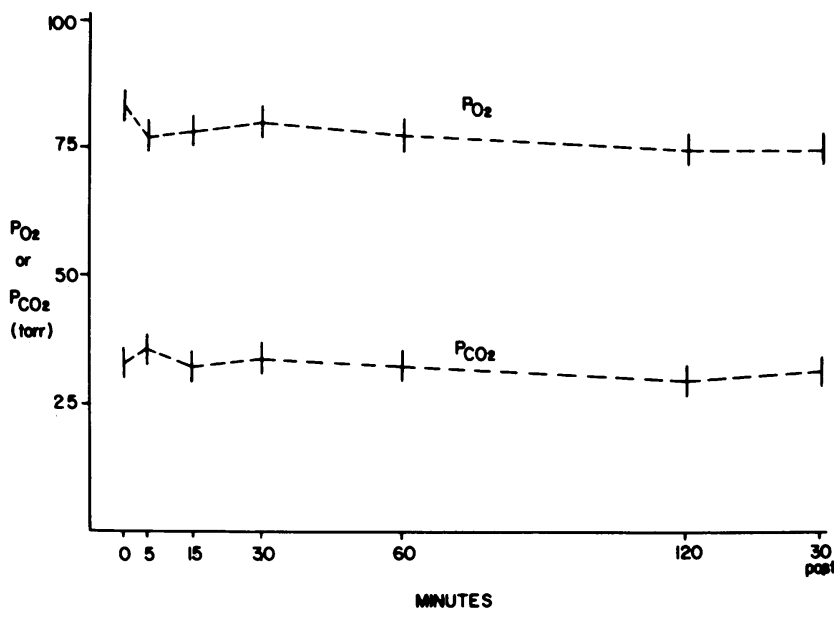

Figure 3. Arterial $\mathrm{PO}_{2}$ and $\mathrm{PCO}_{2}$. There was no significant change in either during dialysis.

with transient hypoxia. Analysis of the data by the 50 compartment ventilation-perfusion distribution of Evans and Wagner and Wagner et al. $(12,13)$ showed that the mean shunt perfusion was uniformly low at $1-3 \%$ throughout the experiment. Mean percent perfusion to regions of low $\dot{\mathrm{V}}_{\mathrm{A}} / \dot{\mathrm{Q}}$ ratio was also uniformly low. Total venous admixture calculated from inert gas retentionexcretion did not change during dialysis. The location and width of the distribution of perfusion to the main $\dot{\mathrm{V}}_{\mathrm{A}} / \mathrm{Q}$ mode was unchanged. The total $(\mathrm{a}-\mathrm{A}) \mathrm{D}$ area and relative $(\mathrm{a}-\mathrm{A}) \mathrm{D}$ area were also unchanged during dialysis. During dialysis there was a trend toward an increase in inert gas dead space, which reached statistical significance only at $120 \mathrm{~min}$. There was a similar trend toward increase in physiological dead space, which also approached significance $(0.05<P<0.1)$ from 30 to $120 \mathrm{~min}$ of dialysis.

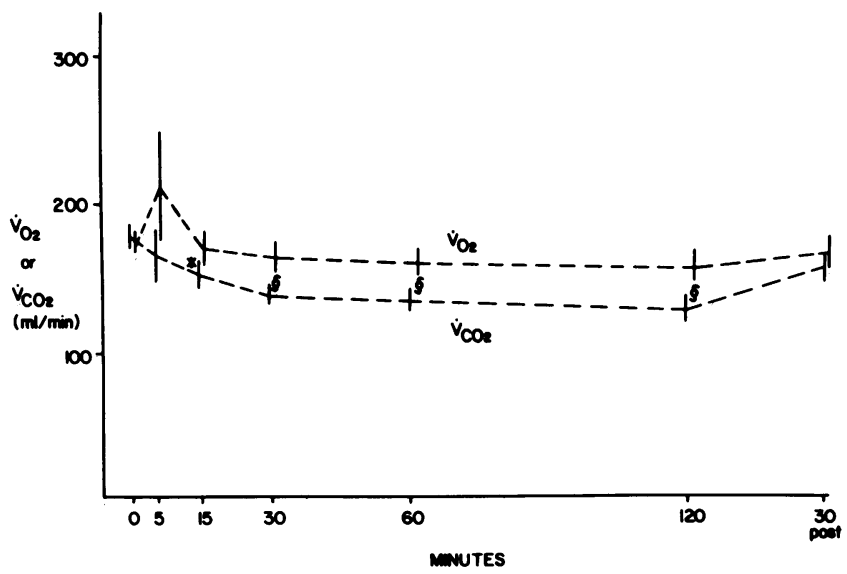

Figure 4. Oxygen consumption $\left(\mathrm{V}_{2}\right)$ and carbon dioxide elimination $\left(\mathrm{V} \mathrm{CO}_{2}\right)$ across the lung. See Fig. 1 legend for explanation of symbols.

\section{Discussion}

It has been known for over 10 years that hypoxia occurs during hemodialysis. In early studies, Bischel et al. (1) measured $\mathrm{PO}_{2}$ before and after dialysis and found a mean drop of $5 \mathrm{mmHg}$. They suggested that the hypoxia was caused by pulmonary microembolization, since no change in $\mathrm{PO}_{2}$ was seen when nylon mesh filters were added. However, Aurigemma et al. (4), in studies comparing blood gases in the presence or absence of filters, found no difference.

In 1977, Craddock et al. $(2,7)$ proposed a leukocyte-mediated pulmonary dysfunction during dialysis. In patients with chronic renal failure they noticed a dramatic decrease in the WBC during the first $30 \mathrm{~min}$ of dialysis. This decrease occurred at the same time as the drop in $\mathrm{PO}_{2}$. They then infused rabbits with plasma that had been incubated with dialyzer membranes and produced similar decreases in $\mathrm{PO}_{2}$ that were prevented by complement inactivation or prior neutropenia. Histological study of the lungs showed intravascular leukostasis. The authors demonstrated that complement activated by the dialyzer membrane caused leukocyte aggregation, and speculated that this led to ventilationperfusion mismatching. This theory was supported by studies showing WBC agglutination after exposure to activated complement $(7,8,15)$, and by studies in dogs that found that the pulmonary vasculature was a major site of the leukocyte sequestration (16).

Other investigators, however cast doubt on this explanation of hypoxemia. Sherlock et al. (3) proposed an alternate theory, based on observations of a decrease in measured respiratory quotient during dialysis. Since $\mathrm{PCO}_{2}$ is very low in acetate solutions, $\mathrm{CO}_{2}$ diffuses into the dialysate and is removed by the dialyzer, so less is exhaled by the lungs. Using the observed reduced value of pulmonary gas exchange ratio $(R)$ in the alveolar gas equation, they calculated a lowering of alveolar oxygen due to alveolar hypoventilation. No change was found in arterialalveolar $\mathrm{O}_{2}$ difference. The $\mathrm{PCO}_{2}$ remained constant as chemoreceptors regulated the ventilation to maintain $\mathrm{P}_{\mathrm{a}} \mathrm{CO}_{2}$. When $\mathrm{CO}_{2}$ was bubbled into the dialysate to prevent $\mathrm{CO}_{2}$ removal by the dialyzer, the $\mathrm{PO}_{2}$ remained stable. Similar results were reported by Aurigemma et al. (4), and others who have come to the same conclusions using bicarbonate instead of acetate in the dialysate (17-19). Dolan et al. (20) measured exhaled and arterial gases in patients on dialysis and found decreased $\mathrm{PO}_{2}$ during acetate dialysis, but not during bicarbonate dialysis. Note that the dead space increased in both situations.

Further evidence favoring the hypoventilation theory comes from the dissociation of WBC-agglutination and hypoxemia in certain situations (21-23). Using three kinds of dialyzers, Dumler and Levin (21) showed that their patients all had similar decreases (7-10\%) in $\mathrm{PO}_{2}$ during dialysis but the leukocyte count dropped with cellulose, did not change with reused cellulose, and increased with polyacrylonitrile. Studies of sequential dialysis by Brautbar et al. (24) also showed dissociation of hypoxia and leukopenia. Patients first underwent ultrafiltration, in which their blood was exposed to the dialysis membrane, but not to dialysate. The 
Table II. Multiple Inert Gas-derived Parameters

\begin{tabular}{|c|c|c|c|c|c|c|c|}
\hline \multirow[b]{2}{*}{ Time } & \multirow{2}{*}{$\frac{\text { Control }}{0}$} & \multicolumn{5}{|l|}{ Dialysis } & \multirow{2}{*}{$\begin{array}{l}\text { Control } \\
150\end{array}$} \\
\hline & & 5 & 15 & 30 & 60 & 120 & \\
\hline \multicolumn{8}{|l|}{ Overall mean } \\
\hline$\dot{V}_{\mathrm{A}} / \dot{Q}$ & $1.54 \pm 0.20$ & $0.85 \pm 0.06$ & $1.41 \pm 0.31$ & $1.81 \pm 0.36$ & $1.69 \pm 0.21$ & $1.96 \pm 0.38$ & $1.45 \pm 0.15$ \\
\hline$\dot{Q}_{\mathrm{S}} / \dot{Q}_{\mathrm{T}}(\%)$ & $2.3 \pm 1.3$ & $1.9 \pm 0.8$ & $1.6 \pm 0.8$ & $2.1 \pm 1.1$ & $2.9 \pm 1.3$ & $1.3 \pm 0.5$ & $1.5 \pm 0.9$ \\
\hline$\dot{Q}_{\text {low }} / \dot{Q}_{\mathrm{T}}(\%)$ & $0.0 \pm 0.0$ & $0.1 \pm 0.1$ & $0.1 \pm 0.1$ & $0.0 \pm 0.0$ & $0.3 \pm 0.3$ & $0.8 \pm 0.6$ & $1.4 \pm 0.7$ \\
\hline$\dot{Q}$ distribution, & $0.92 \pm 0.07$ & $0.52 \pm 0.09$ & $0.90 \pm 0.22$ & $0.97 \pm 0.07$ & $1.19 \pm 0.12$ & $1.17 \pm 0.26$ & $0.98 \pm 0.10$ \\
\hline$\pm \mathrm{SD}$ & $0.64 \pm 0.08$ & $0.59 \pm 0.07$ & $0.66 \pm 0.08$ & $0.66 \pm 0.11$ & $0.54 \pm 0.07$ & $0.68 \pm 0.11$ & $0.65 \pm 0.09$ \\
\hline $\begin{array}{l}\dot{V} \text { distribution, } \\
\quad \text { mean } \dot{V}_{\mathrm{A}} / \dot{Q}\end{array}$ & $2.95 \pm 0.64$ & $2.48 \pm 0.95$ & $2.68 \pm 0.13$ & $3.64 \pm 0.53$ & $3.60 \pm 0.89$ & $3.42 \pm 0.74$ & $3.02 \pm 0.59$ \\
\hline$\pm \mathrm{SD}$ & $1.41 \pm 0.19$ & $1.71 \pm 0.33$ & $2.01 \pm 0.06$ & $1.65 \pm 0.14$ & $1.44 \pm 0.21$ & $1.37 \pm 0.20$ & $1.41 \pm 0.25$ \\
\hline \multicolumn{8}{|l|}{$V_{\mathrm{D}} / V_{\mathrm{T}}(\%)$} \\
\hline Inert gas & $29.2 \pm 6.5$ & $35.0 \pm 3.7$ & $26.6 \pm 6.2^{*}$ & $37.5 \pm 4.8$ & $44.6 \pm 4.1$ & $48.0 \pm 3.0 \ddagger$ & $43.2 \pm 3.8$ \\
\hline Physiological & $49.8 \pm 5.5$ & $53.2 \pm 6.1$ & $56.6 \pm 2.7$ & $57.9 \pm 3.6$ & $59.3 \pm 4.4$ & $62.7 \pm 4.2$ & $55.7 \pm 3.6$ \\
\hline (a-A)D Area & $0.453 \pm 0.127$ & $0.542 \pm 0.181$ & $0.622 \pm 0.120$ & $0.472 \pm 0.093$ & $0.378 \pm 0.081$ & $0.381 \pm 0.120$ & $0.382 \pm 0.090$ \\
\hline \multicolumn{8}{|l|}{ Relative (a-A)D } \\
\hline area $(\%)$ & $43.0 \pm 3.5$ & $40.0 \pm 3.3$ & $35.2 \pm 2.1$ & $40.1 \pm 4.1$ & $43.4 \pm 4.2$ & $48.2 \pm 5.2$ & $46.0 \pm 6.6$ \\
\hline \multicolumn{8}{|l|}{ Predicted $\mathrm{P}_{\mathrm{A}} \mathrm{O}_{2^{-}}$} \\
\hline $\mathrm{P}_{\mathrm{a}} \mathrm{O}_{2}($ torr $)$ & $14.6 \pm 3.1$ & $14.8 \pm 2.8$ & $17.4 \pm 4.6$ & $18.5 \pm 4.7$ & $17.4 \pm 4.2$ & $16.7 \pm 3.2$ & $14.8 \pm 2.6$ \\
\hline \multicolumn{8}{|l|}{ Predicted } \\
\hline$\dot{Q}_{\mathrm{V}} / \dot{Q}_{\mathrm{T}}(\%)$ & $5.9 \pm 1.8$ & $11.2 \pm 4.2$ & $6.1 \pm 2.1$ & $6.7 \pm 1.6$ & $5.5 \pm 1.7$ & $9.9 \pm 3.3$ & $6.4 \pm 2.3$ \\
\hline
\end{tabular}

Values are mean \pm SEM. $\dot{Q}_{\text {low }} / \dot{Q}_{\mathrm{T}}$, flow to regions of $\dot{V}_{\mathrm{A}} \dot{Q}$ between 0.001 and 0.1 . See Table I legend and text for other abbreviations.

WBC decreased, but the $\mathrm{PO}_{2}$ did not decrease. This was followed by conventional dialysis using the same membrane, and the $\mathrm{PO}_{2}$ fell, while the WBC returned to normal.

Recent clinical studies have shown that most hypoxia can be attributed to hypoventilation, but some discrepancies remain. In a careful study Patterson et al. (5) calculated a decrease in mean $R$ from 0.81 to 0.62 in seven patients during hemodialysis. The decrease in ventilation accounted for $83 \%$ of the observed decrease in $\mathrm{PO}_{2}$. Since the $\mathrm{PCO}_{2}$ and calculated alveolar-arterial $\mathrm{PO}_{2}$ difference were unchanged, they found no evidence of ventilation-perfusion mismatching. On the other hand, two studies in patients with acute renal failure show a decreased $\mathrm{PO}_{2}$ during dialysis despite constant mechanical ventilation $(25,26)$. Patients with injured lungs may respond differently than those without any prior pulmonary dysfunction. The WBC agglutination and hypoventilation theories are not incompatable, and the literature suggests that both may play a role. DeBacker et al. (27) dialyzed patients under four conditions: bicarbonate dialysate with polyacryonitrile membrane or with cuprophane membrane, and acetate dialysate with each membrane. The drop in $\mathrm{PO}_{2}$ was greatest when cuprophane membrane was used with acetate dialysate. Hypoxemia occurred but was not as marked with the cuprophane-bicarbonate or acetate-polyacryonitrile combinations. With bicarbonate and polyacryonitrile, there was no change in $\mathrm{PO}_{2}$.

Use of the multiple inert gas elimination technique to quantitate pulmonary gas exchange during dialysis is especially useful because the retention and excretion analysis of the inert gases is only dependent upon inert gas solubility and pulmonary ventilation-perfusion matching and is not affected by the transfer of oxygen and carbon dioxide or inert gases at extrapulmonary sites (13). Loss of inert gases into the dialysate will not affect the inert gas evaluation of pulmonary ventilation-perfusion matching because any peripheral exchange will not affect the mass balance of inert gases in the lung. In this experiment oxygen consumption and $\mathrm{CO}_{2}$ elimination were also measured directly.

Our results showed that during constant controlled ventilation no significant decrease in $\mathrm{P}_{\mathrm{a}} \mathrm{O}_{2}$ occurred during dialysis despite the development of profound leukopenia. The leukopenia 
resolved after $2 \mathrm{~h}$ of dialysis and a rebound leukocytosis occurred after cessation of dialysis.

Hemodynamic changes occurred in both the pulmonary and systemic circulations. A significant elevation in pulmonary artery pressure accompanied the severe neutropenia seen within 5 min after initiation of dialysis in the final six animals. This effect was not seen in the first three dogs, who had only an additional minor drop in leukocyte count due to low predialysis levels. Therefore, the initial pulmonary hypertension appears to be a result of the immediate hemodialysis-induced leukocyte aggregation and pulmonary sequestration. Alternatively, the pulmonary hypertension may be caused by vasoactive substances produced by the interaction of blood and dialysis membrane, as recently suggested by Walker et al. (28). The other major hemodynamic effect of dialysis was a progressive reduction in the cardiac output. The time course of the reduced cardiac output did not correlate with the time course of the neutropenia, and so did not appear to be directly related to the pulmonary leukocyte aggregation. Since the dogs were infused with saline to replace the calculated volume lost during dialysis, and since the pulmonary capillary wedge pressure did not fall, the decreased cardiac output was not caused by volume depletion. The dogs were kept under uniform anesthesia, eliminating variability of depth of anesthesia as a factor. The cardiac output significantly increased after dialysis was terminated, suggesting that the procedure itself was responsible for the decrease in cardiac function. Left ventricular dysfunction has been reported to occur during dialysis (29). One possibility is that the acetate decreases myocardial contractility $(30,31)$, which causes the drop in cardiac output.

These hemodynamic changes during dialysis were not, however, associated with statistically significant changes in the matching of pulmonary ventilation and perfusion. Two aspects of gas exchange should be noted. First, the observed trend toward an increase in dead space may reflect minor worsening in $\dot{V}_{A} /$ $\dot{Q}$ matching due to leukostasis. A similar increase in physiological dead space was seen in studies by Dolan et al. (20) and Patterson et al. (5). The remaining ventilation-perfusion matching was unaltered as the decreased remaining ventilation to perfused lung was accompanied by a reduced cardiac output. Secondly, the observation that the $\mathrm{P}_{\mathrm{a}} \mathrm{CO}_{2}$ did not decrease despite removal of $\mathrm{CO}_{2}$ by the dialyzer is explained by the two influences that in isolation would raise the $\mathrm{PCO}_{2}$. The first of these is the increase in physiological dead space; the second is the increase in mixed venous $\mathrm{PCO}_{2}$ and subsequently arterial $\mathrm{PCO}_{2}$ that occurs when cardiac output diminishes. These influences were opposed to a similar extent by the effect of dialysate removal of $\mathrm{CO}_{2}$, so that the net result was no change in $\mathrm{P}_{\mathrm{a}} \mathrm{CO}_{2}$.

Several parameters obtained from the inert gas elimination technique showed no significant mismatching of ventilation to perfusion during dialysis. When the inert gas data were transformed into a 50-compartment model of ventilation-perfusion matching, the relative percent shunt and perfusion to regions of low $\dot{\mathrm{V}}_{\mathrm{A}} / \mathrm{Q}$ were unchanged. There was no change in the matching of blood flow to ventilation assessed by the standard deviation of the perfusion distribution. Direct analysis of the magnitude of the arterial-alveolar concentration differences for the inert gases showed there was no change in this measurement of ventilation-perfusion matching. Although no single parameter fully characterizes ventilation-perfusion matching, the failure of any of them to change during dialysis provides strong evidence against ventilation-perfusion mismatching that would lead to hypoxemia during hemodialysis in these dogs.

Although the mean $\mathrm{P}_{\mathrm{a}} \mathrm{O}_{2}$ did not change significantly in the entire group of dogs or in the last six dogs (by paired- $t$ test), in three dogs the $\mathrm{P}_{\mathrm{a}} \mathrm{O}_{2}$ fell by $>10$ torr at 5-15 min. Even in the three dogs with transient decrease in $\mathrm{P}_{\mathrm{a}} \mathrm{O}_{2}$ after initiation of dialysis, no ventilation-perfusion mismatch could be detected by the inert gas elimination technique. But at $5 \mathrm{~min}$ the dogs may not have been in a steady state, and small changes in gas exchange could have been undetected. Thus, it is possible that the aggregated leukocytes briefly caused transient hypoxia in some of the dogs. The $\mathrm{P}_{\mathrm{a}} \mathrm{O}_{2}$ quickly returned to normal levels, whereas in spontaneously breathing patients the hypoxemia persists throughout dialysis (5). If leukocyte aggregation plays a role in the hypoxia, it is only a transient one.

In summary, neither hypoxemia nor ventilation-perfusion mismatching for infused inert gases developed in dogs ventilated during a 2-h dialysis against an acetate-contained dialysate. They did demonstrate severe leukopenia, increased pulmonary artery pressure, and increased dead space. These results show that pulmonary leukocyte aggregation does not cause significant ventilation-perfusion mismatching during dialysis. Extrapolation of these results to the situation in which hypoxemia is observed in spontaneously ventilating patients during hemodialysis suggests that such hypoxemia is mainly due to pulmonary hypoventilation.

\section{Acknowledgments}

The authors would like to express their appreciation to Mical Middaugh and Rosa Linda Franada for their excellent technical assistance.

This work was supported by a Clinical Investigator Award NHLBI HL00891-2.

\section{References}

1. Bischel, M. D., F. L. Orrell, B. G. Scoles, J. G. Mohler, and B. H. Barbour. 1973. Effects of microemboli blood filtration during hemodialysis. Trans. Am. Soc. Artif. Intern. Organs. 19:492-497.

2. Craddock, P. R., J. Fehr, K. L. Brigham, R. S. Kronenberg, and H. S. Jacob. 1977. Complement and leukocyte-mediated pulmonary dysfunction in hemodialysis. $N$. Engl. J. Med. 296:769-773.

3. Sherlock, J., J. Ledwith, and J. Letteri. 1977. Hypoventilation and hypoxemia during hemodialysis: reflex response to removal of $\mathrm{CO}_{2}$ across the dialyzer. Trans. Am. Soc. Artif. Intern. Organs. 23:406-410.

4. Aurigemma, N. M., N. T. Feldman, M. Gottlieb, R. Ingram, J. M. Lazarus, and E. G. Lowrie. 1977. Arterial oxygenation during hemodialysis. N. Engl. J. Med. 297:871-873.

5. Patterson, R. W., A. R. Nissenson, J. Miller, R. T. Smith, R. G. Narins, and S. F. Sullivan. 1981. Hypoxemia and pulmonary gas exchange 
during hemodialysis. J. Appl. Physiol. Respir. Environ. Exercise Physiol. 50:259-264.

6. Romaldini, H., R. Rodriguez-Roisin, F. A. Lopez, T. W. Ziegler, H. Z. Bencowitz, and P. D. Wagner. 1982. Mechanisms of hypoxemia during hemodialysis. Am. Rev. Respir. Dis. 125:250. (Abstr.)

7. Craddock, P. R., J. Fehr, A. P. Dalmasso, K. L. Brigham, and H. S. Jacob. 1977. Hemodialysis leukopenia. J. Clin. Invest. 59:878888.

8. Fountain, S. W., B. A. Martin, C. E. Musclow, and J. D. Cooper. 1980. Pulmonary leukostasis and its relationship to pulmonary dysfunction in sheep and rabbits. Circ. Res. 46:175-180.

9. Till, G. O., K. J. Johnson, R. Kunkel, and P. A. Ward. 1982. Intravascular activation of complement and acute lung injury: dependency on neutrophils and toxic oxygen metabolites. J. Clin. Invest. 69:1126-1135.

10. McDonald, J. W. D., M. Ali, E. Morgan, E. R. Townsend, and J. D. Cooper. 1983. Thromboxane synthesis by sources other than platelets in association with complement-induced pulmonary leukostasis and pulmonary hypertension in sheep. Circ. Res. 52:1-6.

11. Wagner, P. D., P. F. Neuman, and R. D. Laravuso. 1974. Simultaneous measurement of eight foreign gases in blood by gas chromatography. J. Appl. Physiol. 36:600-605.

12. Evans, J. W., and P. D. Wagner. 1977. Limits on $\dot{V}_{A} / Q \dot{Q}$ distribution from analysis of experimental inert gas elimination. J. Appl. Physiol. Respir. Environ. Exercise Physiol. 42:889-898.

13. Wagner, P. D., H. A. Saltzman, and J. B. West. 1974. Measurement of continuous distribution of ventilation-perfusion ratios: theory. J. Appl. Physiol. 36:588-599.

14. Hlastala, M. P., and H. T. Robertson. 1978. Inert gas elimination characteristics of the normal and abnormal lung. J. Appl. Physiol. Respir. Environ. Exercise Physiol. 44:258-266.

15. Hosea, S., E. Brown, C. Hammer, and M. Frank. 1980. Role of complement activation in a model of adult respiratory distress syndrome. J. Clin. Invest. 66:375-382.

16. Toren, M., J. Goffinet, and L. Kaplow. 1970. Pulmonary bed sequestration of neutrophils during hemodialysis. Blood. 36:337-340.

17. Eiser, A. R., D. Jayamanne, C. Kokseng, H. Che, R. F. Slifkin, and M. S. Neff. 1982. Contrasting alterations in pulmonary gas exchange during acetate and bicarbonate hemodialysis. Am. J. Nephrol. 2:123127.

18. Nissenson, A. R. 1980. Prevention of dialysis-induced hypoxemia by bicarbonate dialysis. Trans. Am. Soc. Artif. Intern. Organs. 26:339341.
19. Tolchin, N., J. Roberts, and E. Lewis. 1978. Respiratory gas exchange by high-efficiency hemodialyzers. Nephron. 21:137-145.

20. Dolan, M. J., B. J. Whipp, W. D. Davidson, R. E. Weitzman, and K. Wasserman. 1981. Hypopnea associated with acetate hemodialysis: carbon dioxide-flow-dependent ventilation. N. Engl. J. Med. 305:72-75.

21. Dumler, F., and N. Levin. 1979. Leukopenia and hypoxemia. Arch Int. Med. 139:1103-1106.

22. Aljama, P., P. A. E. Bird, M. K. Ward, T. G. Feest, W. Walker, H. Tanboga, M. Sussman, and D. N. S. Kerr. 1978. Haemodialysisinduced leukopenia and activation of complement: effects of different membranes. Proc. Eur. Dialysis Transplant Assoc. 15:144-153.

23. Jacob, A. I., G. Gavellas, R. Zarco, G. Perez, and J. J. Bourgoignie. 1980. Leukopenia, hypoxia, and complement function with different hemodialysis membranes. Kidney Int. 18:505-509.

24. Brautbar, N., J. H. Shinaberger, J. H. Miller, and M. Nachman. 1980. Hemodialysis hypoxemia: evaluation of mechanisms utilizing sequential ultrafiltration-dialysis. Nephron. 26:96-99.

25. Carlon, G. C., P. B. Campfield, P. L. Goldiner, and A. D. Turnbull. 1979. Hypoxemia during hemodialysis. Critical Care Med. 7:497-499.

26. Jones, R. H., J. B. Broadfield, and V. Parsons. 1980. Arterial hypoxemia during hemodialysis for acute renal failure in mechanically ventilated patients: observations and mechanisms. Clin. Nephrol. 14:1822.

27. DeBacker, W. A., G. A. Verpooten, D. J. Borgonjon, P. A. Vermeire, R. R. Lins, and M. E. DeBroe. 1983. Hypoxemia during hemodialysis: effects of different membranes and dialysate compositions. Kidney Int. 23:738-743.

28. Walker, J. F., R. M. Lindsey, A. A. Driedger, W. J. Sibbald, and A. J. Linton. 1984. Hemodialysis induced acute pulmonary hypertension and its relationship to leukopenia and hypoxia. Kidney Int. 25:195. (Abstr.)

29. Mahajan, S. K., D. Long, V. Kinhal, W. A. Briggs, and F. D. McDonald. 1978. Cardiac function changes in patients during hemodialysis. Proc. Dialysis Transplant. Forum. 8:237-241.

30. Aizawa, Y., T. Ohmori, K. Imai, Y. Nara, M. Matsuoka, and Y. Hirasawa. 1977. Depressant action of acetate upon the human cardiovascular system. Clin. Nephrol. 8:477-480.

31. Raja, R., M. Henriquez, M. Kramer, and J. L. Rosenbaum. 1979. Intradialytic hypotension-role of osmolar changes and acetate influx. Trans. Am. Soc. Artif. Intern. Organs. 25:419-421. 